\title{
Anatomia Foliar Comparativa em Espécies de GuanXuma ${ }^{1}$
}

\author{
Comparative Leaf Anatomy of Guanxuma Species
}

CUNHA, V.C. ${ }^{2}$, SANTOS, J.B. ${ }^{3}$, FERREIRA, E.A. ${ }^{4}$, CABRAL, C.M. ${ }^{5}$, SILVA, D.V. ${ }^{6}$ e GANDINI, E.M. ${ }^{7}$

\begin{abstract}
RESUMO - O estudo da anatomia e morfologia das plantas pode ajudar a conhecer prováveis mecanismos que promovem maior capacidade competitiva pelos recursos naturais, principalmente água, luz e nutrientes, além da maior capacidade na retenção e/ou impedimento no processo de penetração de produtos quimicos pelas folhas. Diante disso, o objetivo desta pesquisa foi estudar a anatomia foliar das espécies Sida urens, Sida spinosa e Sida rhombifolia em diferentes etapas de desenvolvimento. Essas espécies foram coletadas em três estádios fenológicos, caracterizados como V1: formação de até 10 folhas completamente expandidas; V2: entre 11 folhas e antes do florescimento; e R: após florescimento. O trabalho foi conduzido em duas etapas, sendo uma relacionada às atividades de cortes anatômicos e a outra às impressões paradérmicas das folhas. A espécie Sida spinosa apresentou maior densidade estomática na fase R. As três espécies apresentaram menor densidade estomática, maior densidade tricomática e parede celular mais espessa no estádio V2. Conclui-se que as três espécies possuem maior conteúdo de cera epicuticular na fase vegetativa, porém $S$. spinosa apresenta relativa diminuição nessa característica na fase reprodutiva.
\end{abstract}

Palavras-chave: estômato, parede celular, Sida rhombifolia, Sida spinosa, Sida urens, tricoma.

ABSTRACT - Plant anatomy and morphology studies may help understand possible mechanisms that promote greater competitive capacity for natural resources, especially water, light, and nutrients, as well as greater capacity in retaining and / or impeding the process of penetration of chemicals through the leaves. Therefore, the objective of this work was to study the leaf anatomy of three species of Sida spp. at different stages of development. These species were collected at three phenological stages, characterized as: V1, formation of up to 10 fully-expanded leaves; V2: formation of around 11 leaves and before flowering, and R: after flowering. The study consisted of two phases, one related to anatomical cut and the other to the paradermic fingerprint of the leaves. The species Sida spinosa showed higher stomatal density at the $R$ stage. The three species presented lower stomatal density, higher trichome density, and thicker cell wall at the V2 stage. It was concluded that the three species have higher epicuticular wax content at the vegetative stage, but the species $\mathbf{S}$. spinosa shows a relative decrease in this characteristic at the reproductive stage.

Keywords: stomata, cell wall, Sida rhombifolia, Sida spinosa, Sida urens, trichome.

\section{INTRODUÇÃO}

Diversas espécies do gênero Sida são consideradas daninhas, principalmente em pastagens e culturas anuais. Podem ser hospedeiras de pragas e doenças, tolerando, mesmo com desenvolvimento limitado, solos pouco férteis e ácidos. Para algumas espécies, a importância relativa é elevada a ponto de justificar a determinação do nível de dano econômico (Fleck et al., 2002). É uma agressiva infestante em diversas culturas

1 Recebido para publicação em 5.2.2012 e aprovado em 1.7.2012.

2 Engōo-Agr ${ }^{0}$., Mestre em Produção Vegetal, Universidade Federal dos Vales do Jequinhonha e Mucuri - UFVJM, <vicunhax@yahoo.com.br>, Faculdade de Ciências Agrárias, Campus II - Rodovia MGT 367 - km 583, nº 5000, Bairro Alto da Jacuba, 39100-000 Diamantina-MG; ${ }^{3}$ Professor Adjunto, Dep. de Agronomia, UFVJM, <barbosa@pq.cnpq.br>; ${ }^{4}$ Pós-Doutorando em Produção Vegetal, UFVJM, <evanderalves@yahoo.com.br>; ${ }^{5}$ Biologa, Mestrando do Programa de Pós-Graduação em Ciência Florestal, UFVJM; ${ }^{6}$ Eng ${ }^{\mathrm{a}}-\mathrm{Agr}{ }^{\mathrm{a}}$., Doutoranda em Fitotecnia, Universidade Federal de Viçosa - DFT/UFV, <danielvaladaos@yahoo.com.br>; ${ }^{7}$ Engenheira Florestal, Mestre em Produção Vegetal, UFVJM, <elizzandragandini@yahoo.com.br>.

Planta Daninha, Viçosa-MG, v. 30, n.2, p. 341-349, 2012 
anuais, principalmente em plantio direto, e também em perenes, pomares, jardins, pastagens e áreas desocupadas, além de dificultar a colheita mecânica em culturas anuais, devido à resistência do caule. Atualmente, algumas espécies têm se destacado como tóxicas a bovinos, apresentando relativa importância econômica no Sul do Brasil, como S. carpinifolia (Furlan et al., 2009; Pedroso et al., 2010).

As plantas do gênero Sida ocorrem em praticamente todo o território nacional, e vários resultados de pesquisa têm sido divulgados relatando a sensibilidade diferencial a diversos herbicidas, principalmente em culturas anuais (Nepomuceno et al., 2007) e pastagens (Tuffi Santos et al., 2004). Entre as prováveis razões para a tolerância das plantas aos produtos cita-se, além das espécies, o estádio de desenvolvimento (Pitelli, 1987).

De acordo com Procópio et al. (2003a), o estudo da anatomia foliar de plantas daninhas destaca-se como uma técnica importante na identificação e descrição de estruturas que podem influenciar a absorção dos herbicidas, além de auxiliar na diferenciação de espécies. Os herbicidas podem penetrar nos tecidos vegetais pelas estruturas aéreas (folhas, caules, flores e frutos) e subterrâneas (raízes, rizomas, estolões, tubérculos, etc.) ou, ainda, estruturas jovens (radículas e caulículos), bem como pelas próprias sementes (Silva \& Silva, 2007). As folhas constituem o principal órgão das plantas daninhas envolvido na penetração de herbicidas aplicados em pós-emergência, e sua morfologia influencia a quantidade do herbicida interceptado e retido (Hess \& Falk, 1990), assim como explica diferentes respostas de espécies de plantas a diversos produtos (Chun et al., 1997).

Com a evolução do conhecimento em tecnologia de aplicação de defensivos e o uso de adjuvantes mais efetivos, como os surfatantes siliconados, observou-se nos tecidos vegetais maior eficiência na penetração das soluções herbicídicas, com relativo entendimento sobre quebra da tensão superficial da gota aspergida, espalhamento do produto sobre a superficie foliar, permitindo maior entrada também pelos estômatos (Stougaard, 1997). Um fator ligado à penetração dos herbicidas pelos estômatos é a cutícula sobre as células-guarda, que parece ser mais fina e mais permeável (menor teor de cera epicuticular), constituindose numa barreira menos rígida à penetração de herbicidas (Hess \& Falk, 1990).

Uma teoria amplamente divulgada é que a maioria das plantas daninhas apresenta em suas folhas estômatos sobre as superficies adaxial e abaxial (anfiestomáticas) (Hess \& Falk, 1990). No entanto, Silva \& Silva (2007) e Velini \& Trindade (1992) relatam que na maioria dessas plantas os estômatos se localizam apenas na face abaxial das folhas (hipoestomáticas) - fato esse evidenciado já na década de 1970 (Meyer et al., 1973). Além disso, nos trabalhos relatados, também é apresentado que nas plantas anfiestomáticas o número de estômatos na face adaxial é normalmente inferior ao da face abaxial. Nesse contexto, é importante considerar que em pulverizações agrícolas a dificuldade de as gotículas atingirem a face abaxial é grande; consequentemente, a importância da absorção pelos estômatos desta face é tida como reduzida, principalmente quando considerada a porcentagem de área coberta que eles representam. Outro fator que leva a se acreditar na pouca importância da absorção de herbicidas pelos estômatos é que estes, em vários horários do dia e durante a noite, para a maioria das espécies vegetais, se encontram fechados. Apesar disso, Taylor et al. (1980) observaram que os estomatos foram a principal via de penetração do herbicida bentazon em folhas de Chenopodium album.

Quando há competição pelos recursos água e luz, a variação na abertura e tipo estomáticos pode representar vantagem competitiva para determinadas espécies. Concenço et al. (2007), trabalhando com plantas de azevém, observaram que o biótipo resistente foi mais eficiente que o suscetivel quanto ao uso da água, devido ao menor tempo de abertura estomática. Já Lima et al. (2010), estudando o padrão estomático em pimentões, verificaram que maiores números e frequências de estômatos em ambas as faces foliares ocorreram em pimentão Magali (altamente suscetivel), com valores significativamente maiores do que em HV-12 (altamente resistente).

As folhas apresentam vários níveis de desenvolvimento de tricomas e glândulas, que podem variar com a espécie. Essas estruturas 
podem promover a retenção das gotas pulverizadas, impedindo que estas alcancem a epiderme das folhas. Mesmo quando os tricomas são simples e aparecem em baixa densidade, ocorre a aderência de gotas sobre eles (Ricotta \& Masiunas, 1992). A eficiência da absorção de herbicidas pelos tricomas e a translocação destes para as células epidérmicas ainda são parcialmente desconhecidas (Hess \& Falk, 1990). Entretanto, de acordo com Hull (1970), parte da absorção de determinadas substâncias pode ocorrer por meio dessas estruturas, apesar de corroborado por poucos autores para soluções contendo herbicidas.

Diante disso, objetivou-se neste trabalho estudar a anatomia foliar de três espécies de Sida spp. de grande ocorrência no Brasil, em diferentes estádios de desenvolvimento, visando melhor compreensão do arranjo dos tecidos e das possiveis barreiras impostas por cada espécie à sua capacidade competitiva.

\section{MATERIAL E MÉTODOS}

O trabalho foi realizado no Laboratório de Anatomia Vegetal da Universidade Federal dos Vales do Jequitinhonha e Mucuri, em Diamantina-MG, com coleta de plantas na Estação Experimental do Moura, em CurveloMG, pertencente à Universidade. Para determinação das espécies, foi realizado trabalho fitossociológico em áreas de pastagens das plantas infestantes ao longo do ano, observando-se maior índice de valor de importância (IVI) para as espécies Sida urens, Sida spinosa e Sida rhombifolia (Tabela 1). Para estimativa do IVI foi adotado o somatório da frequência, da densidade e da abundância relativas, sendo considerada mais importante a espécie com o maior valor final (Muller-Dombois \& Ellenberg, 1974).

Foram coletadas folhas de cada planta em três estádios propostos de desenvolvimento, identificados como V1: formação de até 10 folhas completamente expandidas; V2: entre 11 folhas e antes do florescimento; e R: após florescimento. Foram realizadas duas caracterizações nas folhas, sendo uma para análise por meio de impressões paradérmicas e a outra em cortes anatômicos no sentido transversal foliar. Para avaliação estatística, foi proposta a divisão dos tratamentos em número de nove, constituídos pela combinação de dois fatores (espécie e estádio fenológico) nos três niveis apresentados, com quatro repetições cada, sendo as plantas coletadas de maneira casualizada no campo. Após separação das plantas e identificação, as folhas foram fixadas por 48 horas em FAA 70 (formaldeído, ácido acético e etanol 70\%, 5:5:90, v/v) e conservadas em álcool 70\% (Kraus et al., 1998), até o seu procedimento.

As amostras destinadas à análise foram seccionadas, sendo retirada de cada folha, na porção mediana, uma área de aproximadamente $5 \mathrm{~cm}^{2}$ para observação da superfície foliar, em ambas as faces da lâmina. Na confecção das lâminas utilizou-se o método da impressão da epiderme com cola instantânea (Rodella et al., 1983). As amostras consistiram de quatro fotos de cada face, de cada estádio/ espécie. Os estômatos, as células e os tricomas foram quantificados em microscópio Olympus, nas objetivas de 10 (tricomas) e 40 (estômatos e células), para avaliação do índice e densidade estomática e densidade tricomática.

Os cortes anatômicos com as amostras foliares coletadas foram prensados em isopor e cortados à mão livre no sentido transversal. Os cortes foram imersos em água sanitária até sua completa clarificação e depois lavados em água destilada. A coloração foi realizada com azul de alcian $0,5 \%$ por um minuto, ácido tartárico $2 \%$ por dois minutos e fucsina $0,05 \%$ por 10 segundos, intercalando sempre com água destilada, para remoção do excesso de corante (Kraus et al.,1998). As imagens obtidas no microscópio foram digitalizadas e armazenadas, para medições no programa Image-Pro Plus 4.5. Foram feitas as seguintes medições:

Tabela 1 - Principais espécies de plantas daninhas e respectivas características fitossociológicas em sistema de integração lavoura-pecuária, após 30 dias de plantio de milho e pastagem. Curvelo-MG

\begin{tabular}{|l|r|r|r|r|}
\hline \multicolumn{1}{|c|}{ Plântula } & FRR & DER & ABR & IVI \\
\hline Sida spp $^{1 /}$ & 59,6 & 44,1 & 37,3 & 141,0 \\
\hline Cynodon dactylon & 8,6 & 8,8 & 10,9 & 28,4 \\
\hline Acanthospermum hispidum & 6,7 & 5,9 & 12,7 & 25,3 \\
\hline Demais espécies & 25,0 & 41,2 & 39,1 & 105,2 \\
\hline
\end{tabular}

1/ Sida spp (Sida rhombifolia, Sida spinosa e Sida urens). FRR frequência relativa, DER: densidade relativa, ABR: abundância relativa, IVI: índice de valor de importância. 
espessura da lâmina foliar, epiderme adaxial e abaxial, parede celular adaxial e abaxial, parênquima paliçádico e lacunoso e área do parênquima paliçádico e lacunoso.

Os dados foram submetidos aos testes das pressuposições do modelo matemático (normalidade e homogeneidade das variâncias) e, em seguida, à análise de variância, sendo as médias, quando significativas, comparadas entre si a $5 \%$ pelo teste de Tukey.

\section{RESULTADOS E DISCUSSÃO}

As espécies de Sida caracterizaram-se por possuir folhas anfiestomáticas e estômatos do tipo anomocítico (Figuras 1 e 2). Apesar de pertencerem ao mesmo gênero, as espécies avaliadas apresentaram variações quanto a índice estomático (IE), densidade estomática
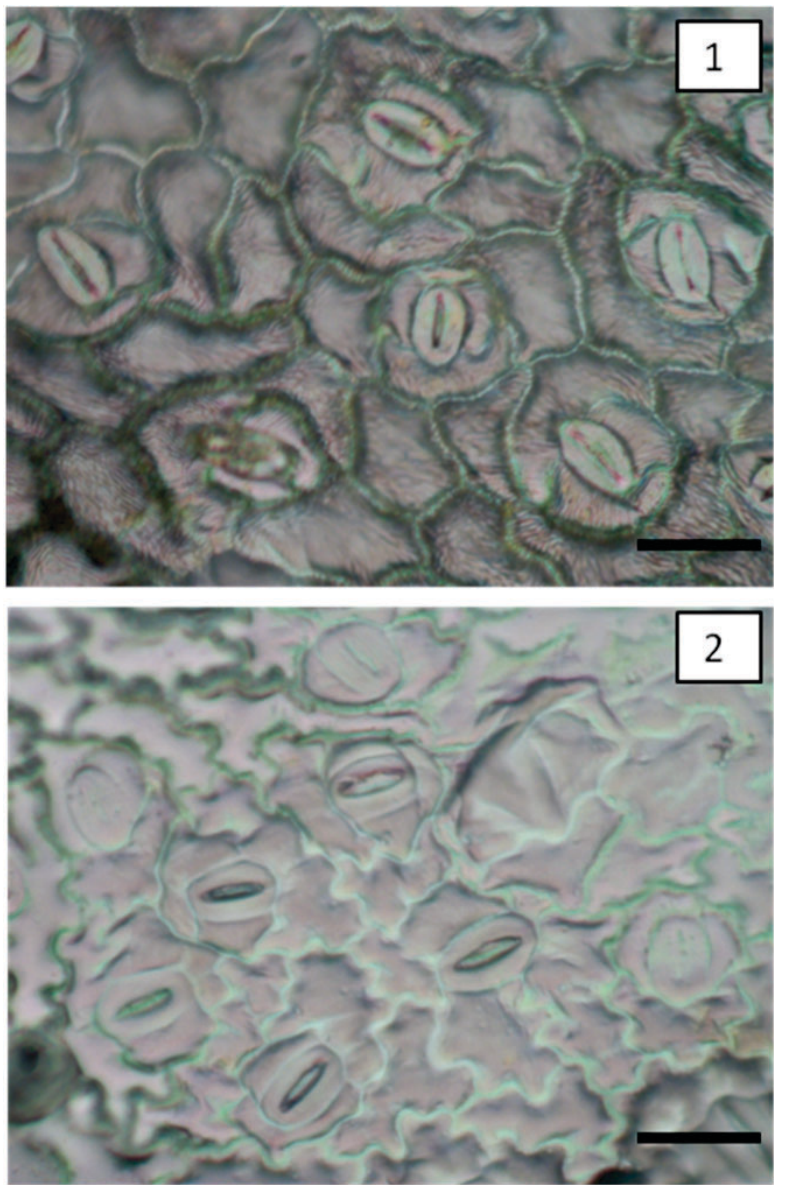

Figura 1 - Superfície adaxial (1) e abaxial (2) de folhas de $S$. rhombifolia V1. Detalhe de estômatos evidenciando o número e tipo estomático anomocítico. (Barra $=30 \mu \mathrm{m})$.
(DE), densidade tricomática (DT), espessura da lâmina foliar (ELF), espessura da epiderme (EE), espessura da parede celular (EPC), espessura
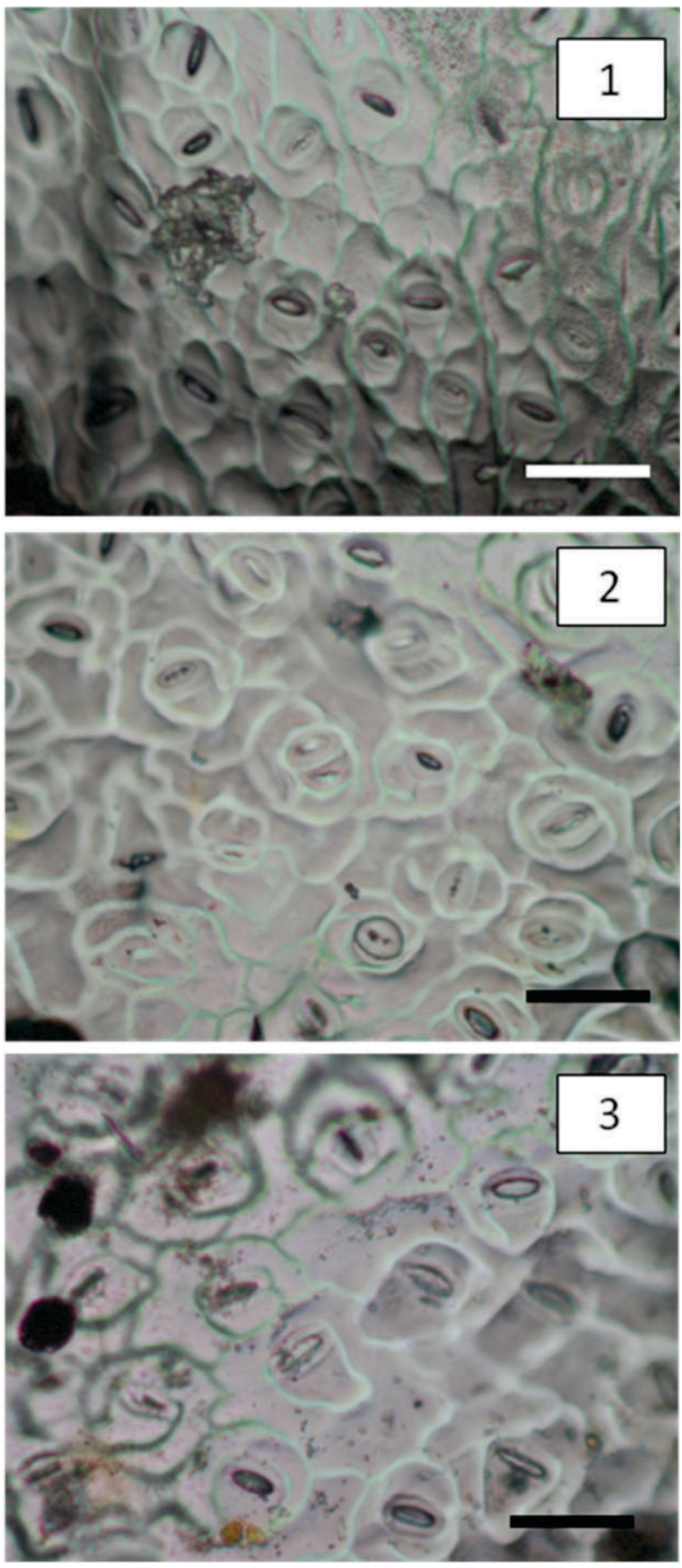

Figura 2 - Face abaxial de Sida urens em três estádios propostos para o desenvolvimento, sendo V1 (até 10 folhas completamente expandidas - 1), V2 (de 11 folhas completamente expandidas até florescimento - 2) e $R$ (após florescimento - 3). $($ Barra $=30 \mu \mathrm{m})$. 
dos parênquimas (EP) e área dos parênquimas (AP).

Para o IE na face abaxial das folhas, observaram-se menores valores para $S$. rhombifolia no estádio V1, sem diferir de S. urens (Tabela 2). Para a face adaxial, o valor de IE foi superior em $S$. urens no estádio V1 e superior em $S$. spinosa no estádio $R$, quando comparado ao das demais espécies V2 (Tabela 2). S. rhombifolia apresentou menor quantidade de estômatos na face adaxial (Figura 1). Procópio et al. (2003b) observaram valores de 8,79 e 24,90 de IE nas faces adaxial e abaxial, respectivamente, de diferentes espécies de plantas daninhas, entre elas Sida glaziovii, corroborando as médias das espécies em estudo.

Entre os estádios avaliados, as espécies S. rhombifolia na face adaxial e $S$. urens em ambas as faces apresentaram maior IE no início do desenvolvimento (V1) (Tabela 2). Para S. spinosa, observou-se menor IE na fase V2 em relação às demais e elevado valor para IE na fase reprodutiva na superfície adaxial (Tabela 2).
A densidade estomática das três espécies foi equivalente em ambas as superficies, exceto para S. spinosa no estádio V1 (Tabela 2). No estádio R, S. spinosa apresentou maior densidade estomática em ambas as faces. Procópio et al. (2003b) determinaram que a baixa densidade estomática em Sida glaziovii foi considerada uma das principais barreiras à penetração de herbicidas. Para Tuffi Santos et al. (2006), a alta densidade pode favorecer a penetração do glyphosate em plantas de eucalipto nas quais a presença de estômatos seja grande, principalmente na face adaxial da epiderme foliar, onde o contato com a calda herbicida aplicada é mais provável. A alta densidade estomática de $S$. spinosa pode ser considerada um fator positivo do ponto de vista do controle da espécie em se tratando de aplicação de herbicidas, pois a absorção tende a ser maior.

Segundo Mauseth (1988) e Solereder (1908), a família Malvaceae é caracterizada por possuir tricomas estelares e organismos secretores com conteúdo mucilaginoso, apesar de nem todos os membros da família manifestarem essas características. Em trabalho de

Tabela 2 - Índice estomático, densidade estomática e densidade tricomática das superfícies adaxial e superfície abaxial das três espécies do gênero Sida, mensurados em três estádios fenológicos. Diamantina-MG

\begin{tabular}{|c|c|c|c|c|c|c|}
\hline \multirow{3}{*}{ Espécie } & \multicolumn{3}{|c|}{ Superfície adaxial } & \multicolumn{2}{|c|}{ Superfície abaxial } & \\
\hline & \multicolumn{6}{|c|}{ Índice estomático ${ }^{\underline{1}}$} \\
\hline & $\mathrm{V} 1^{2 / /}$ & $\mathrm{V} 2$ & $\mathrm{R}$ & V1 & $\mathrm{V} 2$ & $\mathrm{R}$ \\
\hline S. rhombifolia & $17,5 \mathrm{bA}$ & $5,0 \mathrm{aB}$ & $11,0 \mathrm{bB}$ & $23,7 \mathrm{bA}$ & $20,5 \mathrm{aA}$ & $25,5 \mathrm{aA}$ \\
\hline S. spinosa & $12,0 \mathrm{bB}$ & $5,2 \mathrm{aC}$ & $19,0 \mathrm{aA}$ & $35,7 \mathrm{aA}$ & $11,5 \mathrm{abB}$ & $25,2 \mathrm{aA}$ \\
\hline S. urens & $24,0 \mathrm{aA}$ & $6,5 \mathrm{aB}$ & $10,2 \mathrm{bB}$ & $30,2 \mathrm{abA}$ & $13,9 \mathrm{bB}$ & $15,5 \mathrm{aB}$ \\
\hline \multirow[t]{2}{*}{$\mathrm{CV}(\%)$} & \multicolumn{3}{|c|}{28,1} & \multicolumn{3}{|c|}{30,1} \\
\hline & \multicolumn{6}{|c|}{ Densidade estomática (est $\mathrm{mm}^{-2}$ ) } \\
\hline S. rhombifolia & $171,7 \mathrm{aA}$ & $37,5 \mathrm{aB}$ & $88,5 \mathrm{bAB}$ & $337,0 \mathrm{abA}$ & $138,5 \mathrm{aB}$ & $195,2 \mathrm{bAB}$ \\
\hline S. spinosa & $69,5 \mathrm{bB}$ & $34,2 \mathrm{aB}$ & $217,7 \mathrm{aA}$ & $455,5 \mathrm{aA}$ & $98,0 \mathrm{aB}$ & $376,7 \mathrm{aA}$ \\
\hline S. urens & $148,5 \mathrm{abA}$ & $54,2 \mathrm{aB}$ & $74,5 \mathrm{bAB}$ & $245,5 \mathrm{bA}$ & $65,0 \mathrm{aB}$ & $149,2 \mathrm{bAB}$ \\
\hline \multirow[t]{2}{*}{ CV $(\%)$} & \multicolumn{3}{|c|}{49,8} & \multicolumn{3}{|c|}{42,6} \\
\hline & \multicolumn{6}{|c|}{ Densidade tricomática (tri $\left.\mathrm{mm}^{-2}\right)$} \\
\hline S. rhombifolia & $5,7 \mathrm{aB}$ & $52,0 \mathrm{bA}$ & $7,2 \mathrm{aB}$ & $9,2 \mathrm{bA}$ & $12,5 \mathrm{bA}$ & 32,7 aA \\
\hline S. spinosa & $16,5 \mathrm{aB}$ & $59,7 \mathrm{abA}$ & $6,0 \mathrm{aB}$ & $81,5 \mathrm{aA}$ & $61,5 \mathrm{aA}$ & $17,5 \mathrm{aB}$ \\
\hline S. urens & $21,0 \mathrm{aB}$ & $81,7 \mathrm{aA}$ & $30,7 \mathrm{aB}$ & $48,5 \mathrm{abAB}$ & 77,7 aA & $17,2 \mathrm{aB}$ \\
\hline $\mathrm{CV}(\%)$ & \multicolumn{3}{|c|}{45,9} & \multicolumn{3}{|c|}{58,8} \\
\hline
\end{tabular}

${ }^{1 /} \mathrm{O}$ índice estomático (I) foi calculado pela expressão: $\mathrm{I}(\%)=\mathrm{S} /(\mathrm{S}+\mathrm{E}) \times 100$, sendo $\mathrm{S}$ o número de estômatos por unidade de área foliar e $\mathrm{E}$ o número de células epidérmicas na mesma área. ${ }^{2 /} \mathrm{V} 1$ : formação de até 10 folhas completamente expandidas; V2: entre 11 e antes do florescimento; R: após florescimento. Médias seguidas pela mesma letra na linha (maiúscula) e na coluna (minúscula), para cada variável e posicionamento na folha (adaxial ou abaxial), não diferem entre si a 5\% pelo teste de Tukey. 
Albert \& Victoria Filho (2002), a superficie adaxial de $S$. rhombifolia apresentou tricomas estelares e simples em pouca quantidade, tanto curtos como longos e glandulares.

As espécies apresentaram lâmina foliar com espessura de 151,5, 179,9 e 183, $1 \mu \mathrm{m}$ em S. rhombifolia, S. spinosa e $S$. urens, respectivamente (Tabela 3). Não houve diferença estatística entre as espécies $S$. spinosa e $S$. urens quanto à espessura média da lâmina foliar, e na espécie S. rhombifolia o estádio V2 apresentou a menor espessura de lâmina foliar (Figura 3). As epidermes das três espécies são uniestratificadas, sendo a face adaxial mais espessa em relação à abaxial. Segundo Procópio et al. (2003b), Sida glaziovii possui as mesmas características em relação às faces da epiderme, porém a espessura média em ambas as faces é de 127,23 $\mu \mathrm{m}$, observandose que as folhas foram coletadas do terceiro ao quinto nó, quando elas estavam completamente expandidas. As espessuras das epidermes adaxial e abaxial não diferiram entre as espécies. Na espécie S. urens, o estádio V1 apresentou o menor valor da espessura em ambas as faces da folha (Tabela 4), enquanto na face adaxial não houve diferença significativa de espessura da parede celular entre S. rhombifolia e $S$. urens nas fases V1 e R.

O mesofilo das espécies é dorsiventral, com o parênquima paliçádico apresentando camadas de células com espessura total média de 65,2, 80,1 e 86,7 $\mu \mathrm{m}$ nas espécies S. rhombifolia, S. spinosa e S. urens,

Tabela 3 - Espessura da lâmina foliar das três espécies do gênero Sida, mensurada em três estádios fenológicos. Diamantina-MG

\begin{tabular}{|l|c|c|c|}
\hline \multirow{2}{*}{ Espécie } & \multicolumn{3}{|c|}{${\text { Estádio fenológico }{ }^{1 /}}^{-}$} \\
\cline { 2 - 4 } & \multicolumn{3}{|c|}{ Espessura da lâmina foliar } \\
\cline { 2 - 4 } & $144,5 \mathrm{bAB}$ & $174,2 \mathrm{aA}$ & $135,7 \mathrm{aB}$ \\
\hline S. rhombifolia & $186,7 \mathrm{aA}$ & $169,5 \mathrm{aA}$ & $183,5 \mathrm{aA}$ \\
\hline S. spinosa & $172,0 \mathrm{abA}$ & $170,5 \mathrm{aA}$ & $206,7 \mathrm{aA}$ \\
\hline S. urens & \multicolumn{3}{|c}{12,3} \\
\hline CV $(\%)$ & \multicolumn{3}{|c|}{} \\
\hline
\end{tabular}

1/ V1: formação de até 10 folhas completamente expandidas; V2 entre 11 folhas e antes do florescimento; R: após florescimento. Médias seguidas pela mesma letra na linha (maiúscula) e na coluna (minúscula), para cada variável, não diferem entre si a $5 \%$ pelo teste de Tukey. respectivamente (Tabela 5), e espessura média do parênquima lacunoso de 46,3, 60,4 e 55,2 $\mu \mathrm{m}$ nas respectivas espécies (Tabela 5). Procópio et al. (2003b) encontraram em $S$. glaziovii os seguintes valores médios de espessura: $52,0 \mu \mathrm{m}$ no parênquima paliçádico e $45,5 \mu \mathrm{m}$ no parênquima lacunoso. A espessura dos parênquimas paliçádico e lacunoso não diferiu significativamente no estádio V2
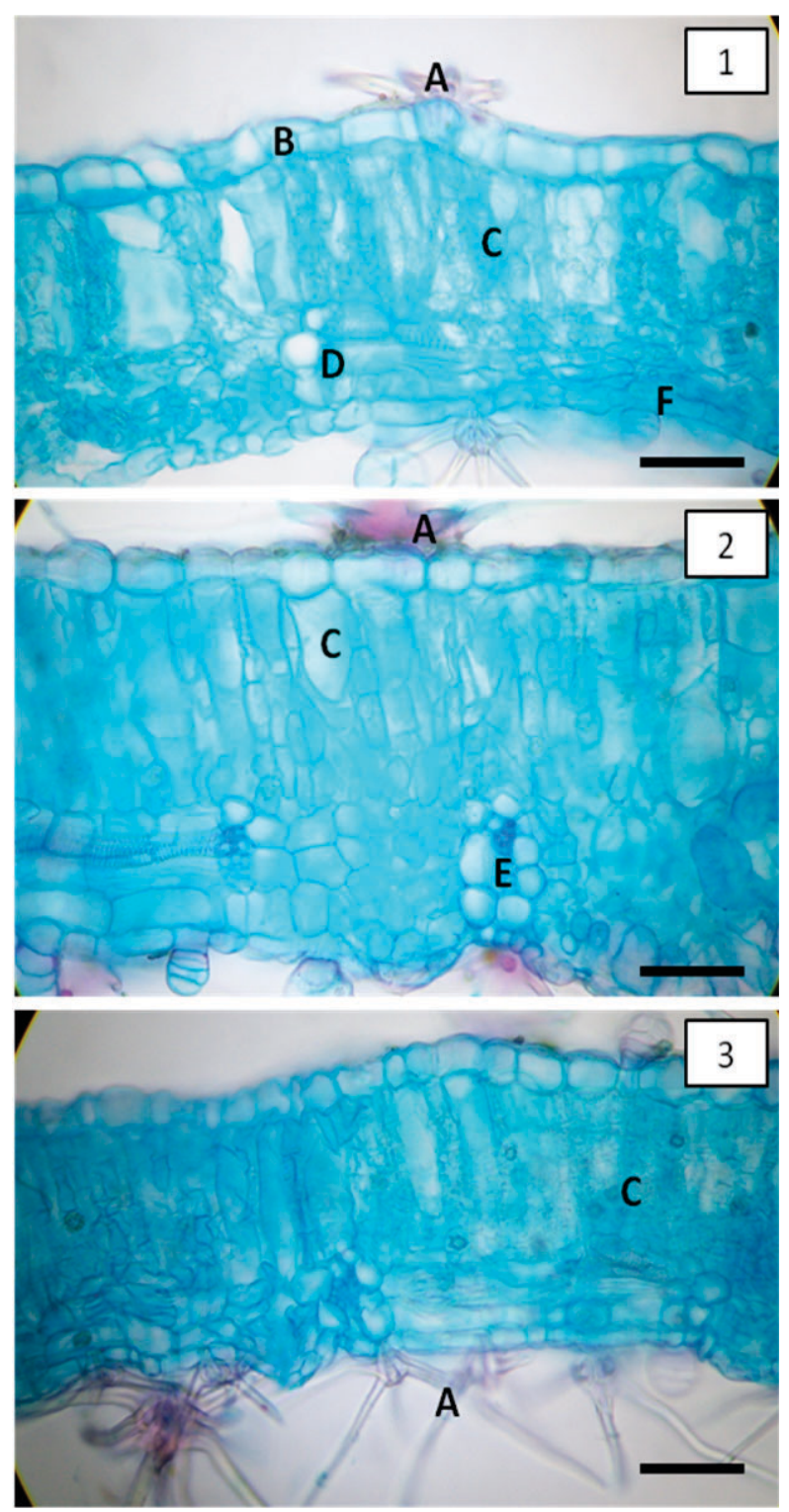

Figura 3 - Lâmina foliar de S. rhombifolia, nos estádios V1 (1), V2 (2) e R (3). A: pelo estrelado (tricoma ramificado); B: epiderme adaxial; $\mathrm{C}$ : parênquima paliçádico, D: parênquima lacunoso; E: feixe vascular; F: epiderme abaxial. (Barra = $30 \mu \mathrm{m})$. 
Tabela 4 - Espessura da epiderme e da parede celular nas superfícies adaxial e abaxial das três espécies do gênero Sida, mensurada em três estádios fenológicos. Diamantina-MG

\begin{tabular}{|c|c|c|c|c|c|c|}
\hline \multirow{3}{*}{ Espécie } & \multicolumn{3}{|c|}{ Superfície adaxial } & \multicolumn{3}{|c|}{ Superfície abaxial } \\
\hline & \multicolumn{6}{|c|}{ Espessura da epiderme $^{1 /}(\mu \mathrm{m})$} \\
\hline & V1 & $\mathrm{V} 2$ & $\mathrm{R}$ & V1 & $\mathrm{V} 2$ & $\mathrm{R}$ \\
\hline S. rhombifolia & $13,7 \mathrm{aA}$ & $16,5 \mathrm{aA}$ & $15,2 \mathrm{aA}$ & $8,2 \mathrm{aA}$ & $8,5 \mathrm{aA}$ & $12,7 \mathrm{aA}$ \\
\hline S. spinosa & $14,7 \mathrm{aA}$ & $15,7 \mathrm{aA}$ & $15,0 \mathrm{aA}$ & $7,5 \mathrm{aA}$ & $5,7 \mathrm{aA}$ & $10,0 \mathrm{aA}$ \\
\hline S. urens & $13,0 \mathrm{aB}$ & $15,5 \mathrm{aAB}$ & $17,7 \mathrm{aA}$ & $6,0 \mathrm{aB}$ & $9,0 \mathrm{aAB}$ & $13,2 \mathrm{aA}$ \\
\hline \multirow[t]{2}{*}{$\mathrm{CV}(\%)$} & \multicolumn{3}{|c|}{13,7} & \multicolumn{3}{|c|}{29,5} \\
\hline & \multicolumn{6}{|c|}{ Espessura da parede celular $(\mu \mathrm{m})$} \\
\hline S. rhombifolia & $1,7 \mathrm{aB}$ & $3,7 \mathrm{abA}$ & $1,2 \mathrm{aB}$ & $1,0 \mathrm{aB}$ & $2,0 \mathrm{aA}$ & $0,7 \mathrm{bB}$ \\
\hline S. spinosa & $2,0 \mathrm{aA}$ & $2,7 \mathrm{bA}$ & $1,5 \mathrm{aA}$ & $1,0 \mathrm{aA}$ & $1,0 \mathrm{bA}$ & $1,0 \mathrm{abA}$ \\
\hline S. urens & $1,7 \mathrm{aB}$ & $4,7 \mathrm{aA}$ & $2,0 \mathrm{aB}$ & $1,0 \mathrm{aB}$ & $1,7 \mathrm{aA}$ & $1,5 \mathrm{aAB}$ \\
\hline $\mathrm{CV}(\%)$ & \multicolumn{3}{|c|}{45,2} & \multicolumn{3}{|c|}{24,9} \\
\hline
\end{tabular}

1/ V1: formação de até 10 folhas completamente expandidas; V2: entre 11 folhas e antes do florescimento; R: após florescimento. Médias seguidas pela mesma letra na linha (maiúscula) e na coluna (minúscula), para cada variável, não diferem entre si a $5 \%$ pelo teste de Tukey.

Tabela 5 - Espessura e área de parênquimas paliçádico e lacunoso de três espécies do gênero Sida, mensuradas em três estádios fenológicos. Diamantina-MG

\begin{tabular}{|c|c|c|c|c|c|c|}
\hline \multirow{3}{*}{ Espécie } & \multicolumn{3}{|c|}{ Parênquima Paliçádico } & \multicolumn{3}{|c|}{ Parênquima Lacunoso } \\
\hline & \multicolumn{6}{|c|}{ Espessura $^{1 /}(\mu \mathrm{m})$} \\
\hline & V1 & V2 & $\mathrm{R}$ & V1 & V2 & $\mathrm{R}$ \\
\hline S. rhombifolia & $64,2 \mathrm{bB}$ & $85,5 \mathrm{aA}$ & $45,7 \mathrm{bB}$ & $39,7 \mathrm{bA}$ & $49,5 \mathrm{aA}$ & $49,7 \mathrm{bA}$ \\
\hline S. spinosa & $86,2 \mathrm{aA}$ & $78,2 \mathrm{aA}$ & $75,7 \mathrm{aA}$ & $59,2 \mathrm{aA}$ & $56,0 \mathrm{aA}$ & $66,0 \mathrm{abA}$ \\
\hline S. urens & $90,7 \mathrm{aA}$ & $93,2 \mathrm{aA}$ & $76,0 \mathrm{aA}$ & $48,0 \mathrm{abB}$ & $47,5 \mathrm{aB}$ & $70,0 \mathrm{aA}$ \\
\hline \multirow[t]{2}{*}{$\mathrm{CV}(\%)$} & \multicolumn{3}{|c|}{15,2} & \multicolumn{3}{|c|}{19,5} \\
\hline & \multicolumn{6}{|c|}{ Área $\left(\mu \mathrm{m}^{2}\right)$} \\
\hline S. rhombifolia & $29807 \mathrm{aAB}$ & $371167 \mathrm{aA}$ & $17786 \mathrm{aB}$ & $19902 \mathrm{aA}$ & 23019 aA & $19829 \mathrm{bA}$ \\
\hline S. spinosa & $39375 \mathrm{aA}$ & $36453 \mathrm{aA}$ & $36014 \mathrm{aA}$ & $28435 \mathrm{aA}$ & $23468 \mathrm{aA}$ & $28956 \mathrm{abA}$ \\
\hline S. urens & $41781 \mathrm{aA}$ & $29215 \mathrm{aA}$ & $38901 \mathrm{aA}$ & $20012 \mathrm{aB}$ & $13906 \mathrm{aB}$ & $30785 \mathrm{aA}$ \\
\hline $\mathrm{CV}(\%)$ & \multicolumn{3}{|c|}{24,4} & \multicolumn{3}{|c|}{24,8} \\
\hline
\end{tabular}

1/V1: formação de até 10 folhas completamente expandidas; V2: entre 11 folhas e antes do florescimento; R: após florescimento. Médias seguidas pela mesma letra na linha (maiúscula) e na coluna (minúscula), para cada variável, não diferem entre si a 5\% pelo teste de Tukey.

para as três espécies. S. rhombifolia obteve maior espessura do parênquima paliçádico no estádio V2, quando comparado aos estádios V1 e R. Já $S$. urens apresentou maior espessura do parênquima lacunoso no estádio $R$, quando comparado aos estádios V1 e V2 (Tabela 5).

A área do parênquima paliçádico não diferiu entre as espécies em $S$. rhombifolia; no estádio V2 determinou-se maior área do que no estádio $R$, provavelmente pelo fato de a coleta das folhas ter sido realizada em uma mesma intensidade luminosa. Em trabalhos com folhas "de sol" de acerola, o parênquima paliçádico apresentou-se mais alongado, em comparação com as folhas de sombra (Silva \& Silva, 2010). Resultados semelhantes foram encontrados nos estudos de Noveline \& Conforto (2006) em seringueiras. No estádio $\mathrm{R}$, houve diferença entre as espécies quanto à área do parênquima lacunoso, tendo S. rhombifolia a menor área. A espécie $S$. urens apresentou menor área do parênquima lacunoso na fase (Tabela 5).

Com base nas características anatômicas apresentadas, S. spinosa foi a espécie que obteve a maior diferença anatômica, entre as 
outras, apresentando maior densidade de estômatos na fase $R$, tanto na superfície adaxial quanto na abaxial. O uso de técnicas de aplicação que facilitem o molhamento das folhas das espécies de guanxuma avaliadas, como regulagem da pressão do pulverizador, escolha da ponta de pulverização e uso de surfatantes, deve proporcionar maior penetração dos herbicidas, pois esse estádio apresenta as características menos suscetiveis.

Entre outros componentes, os resultados desta pesquisa sobre as características anatômicas esclarecem as diferenças de sensibilidade das espécies do gênero Sida a herbicidas diante das diferentes plantas cultivadas e contribuem para novas estratégias de controle dessas plantas.

\section{AGRADECIMENTOS}

À Coordenação de Aperfeiçoamento de Pessoal de Nivel Superior (Capes), ao Conselho Nacional de Desenvolvimento Científico e Tecnológico (CNPq) e à Fundação de Amparo à Pesquisa do Estado de Minas Gerais (FAPEMIG), pelo apoio financeiro na execução deste trabalho.

\section{LITERATURA CITADA}

ALBERT, L. H. B.; VICTORIA FILHO, R. Características morfológicas da cutícula foliar e efeitos de adjuvantes no controle químico de três espécies de guanxumas. Ci. Agrotec., v. 26, n. 5 , p. $888-899,2002$.

CHUN, J. C. et al. Physiological responses of Rehmannia glutinosa to paraquat and its tolerance mechanisms.

Pestic. Biochem. Physiol., v. 59, n. 1, p. 51-63, 1997.

CONCENÇO, G. et al. Uso da água em biótipos de azevém (Lolium multiflorum) em condição de competição.

Planta Daninha, v. 25, n. 3, p. 449-455, 2007.

FLECK, N. G.; RIZZARDI, M. A.; AGOSTINETTO, D. Nível do dano econômico como critério para tomada de decisão no controle de guanxuma em soja. Planta Daninha, v. 20, n. 3 , p. $421-429,2002$

FURLAN, F. H. et al. Spontaneous lysosomal storage disease caused by Sida carpinifolia (Malvaceae) poisoning in cattle. Veter. Pathol., v. 46, n. 2, p. 343-347, 2009.

HESS, F. D.; FALK, R. H. Spontaneous lysosomal storage disease caused by Sida carpinifolia (Malvaceae) poisoning in cattle. Weed Sci., v. 38, n. 3, p. 280-288, 1990.
HULL, H. M. Leaf structure as related to absorption of pesticides and other compounds. Res. Rev., v. 31, n. 1, p. $1-155,1970$.

KRAUS J. E. et al. Astra blue and basic fuchsin double staining of plant materials. Biot. Histochem., v. 73, n. 5, p. 235-243, 1998.

LIMA, M. L. P.; LOPES, C. A.; CAFE FILHO, A. C. Padrão estomático de Capsicum ssp. resistentes e suscetíveis a Oidiopsis haplophylli. Summa Phytopathol., v. 36, n. 1, p. $1-29,2010$

MAUSETH, J. D. Plant anatomy. California: Benjamin/ Cummings Publishing Company, 1988. 560 p.

MEYER, B. et al. Introdução à fisiologia vegetal. 2.ed. Lisboa: Fundação Caloustre Gulbenkian, 1973. 710 p.

MULLER-DOMBOIS, D.; ELLENBERG, H. Aims and methods of vegetation ecology. New York: John Wiley, 1974. 547 p.

NEPOMUCENO, M. et al. Períodos de interferência das plantas daninhas na cultura da soja nos sistemas de semeadura direta e convencional. Planta Daninha, v. 25, n. 1, p. 43-50, 2007.

NOVELINE, A. C.; CONFORTO, E. C. Comparação anatômica e fisiológica entre folhas de seringueira de sol e de sombra. R. Hispeci. Lema, v. 9, n. 1, p. 28-30, 2006

PEDROSO, M. O. et al. Doença do armazenamento lisossomal induzida pelo consumo de Sida carpinifolia em bovinos do Rio Grande do Sul. Pesq. Veter. Bras., v. 30, n. 10 , p. $816-826,2010$

PITELLI, R. A. Competição e controle das plantas daninhas em áreas agrícolas. Série Técnica IPEF, v.4, n.12, p.1-24, 1987.

PROCÓPIO, S. O. et al. Anatomia foliar de plantas daninhas do Brasil. Viçosa, MG: Universidade Federal de Viçosa, 2003a. v. 1. 118 p.

PROCÓPIO, S. O. et al . Estudos anatômicos de folhas de espécies de plantas daninhas de grande ocorrência no Brasil. V - Leonurus sibiricus, Leonotis nepetaefolia, Plantago tomentosa e Sida glaziovii. Planta Daninha, v. 21, n. 3, p. 403-411, 2003 b .

RICOTTA, J. A.; MASIUNAS, J. B. Relantionship of leaf surface characteristics to acifluorfen tolerance in tomato (Lycopersicon esculentum) and related species. Weed Sci., v. 40, n. 3 , p. $402-407,1992$.

RODELLA, R. A. et al. Anatomia comparativa foliar e caulinar de duas espécies daninhas de Merremia (Convolvulaceae). Científica, v. 21, n. 2, p. 345-353, 1983. 
SILVA, A. A.; SILVA, J. F. Tópicos em manejo de plantas daninhas. Viçosa, MG: Universidade Federal de Viçosa, 2007. $367 \mathrm{p}$

SILVA, J. M.; SILVA, M. C. F. Determinação dos teores de clorofilas, estômatos e parênquima em aceroleira. R. Hispeci. Lema, v. 1, n. 1, p. 1-7, 2010.

STOUGAARD, R. M. Adjuvant combinations with quizalofop for wild oat (Avena fatua) control in pepermit (Mentha piperita). Weed Technol., v. 11, n. 1, p. 45-50, 1997.

TAYLOR, F. E.; COBB, A. H.; DAVIES, L. G. The effects of bentazon on stomatal behavior in Chenopodium album $\mathrm{L}$.

New Phytol., v. 85, n. 3, p. 369-376, 1980.
TUFFI SANTOS, L. D. et al . Características da epiderme foliar de eucalipto e seu envolvimento com a tolerância ao glyphosate. Planta Daninha, v. 24, n. 3, p. 503-520, 2006.

TUFFI SANTOS, L. D. et al. Levantamento fitossociológico em pastagens degradadas sob condições de várzea.

Planta Daninha, v. 22, n. 3, p. 343-349, 2004.

VELINI, E. D.; TRINDADE, M. L. B. Comportamento de herbicidas na planta. Épocas de aplicação de herbicidas. In: SIMPÓSIO NACIONAL SOBRE MANEJO INTEGRADO DE PLANTAS DANINHAS EM HORTALIÇAS, 1992, Botucatu, SP. Anais... Botucatu: UNESP, 1992. p. 65-86. 